\title{
Para uma Clínica Psicanalítica das Psicoses ${ }^{1}$
}

\author{
Alfredo Jerusalinsky
}

Nosso assunto, hoje, trata das psicoses e autismos infantis. Assim enunciada a questão, fica, certamente, marcada uma diferença, justamente porque não se inclui dentro das psicoses o autismo infantil precoce como mais uma delas. Considero - junto com muitos outros - que se trata de estruturas psíquicas diferentes. Ou seja, o autismo não é uma variedade dentro das psicoses, mas é outra coisa, outra forma de organização psíquica.

$\mathrm{Na}$ verdade, não é nada fácil ser autista. Eu diria também que é mais fácil ser criança psicótica do que ser criança neurótica. Não estou falando de nenhum estudo de probabilidade, de nenhum estudo estatístico. Quando me refiro à facilidade, refiro-me à facilidade lógica, ao fato de que é menos complexo ser psicótico do que ser neurótico para uma criança. É menos complexo, o que não quer dizer que seja fácil do ponto de vista da vida. A vida se torna complicada quando a criança é psicótica. É mais fácil do ponto de vista de que as operações lógicas implicadas para que venha a se produzir um sujeito psicótico infantil são mais ou menos simples. Pelo menos mais simples do que as necessárias para produzir um neurótico ou um autista.

É necessário trabalhar muito para que se instale um sujeito 
neurótico. E, paradoxalmente, é também necessário trabalhar muito para que se instale um autismo. Por sinal, não estamos dizendo que alguém nos fabrique deliberadamente; referimo-nos ao fato de que nos dão trabalho. Aqui vocês notaram que eu estou falando de um autismo e não de um sujeito autista, porque no caso do autismo não dá para falar em sujeito, não há sujeito, pois não se constitui no autismo isso que podemos chamar de estrutura mínima, que é a estrutura do fantasma. É esse o único quadro clínico, a única forma de funcionamento mental, em que não há fantasma. Porque essa estrutura mínima, o fantasma, existe na neurose, na perversão e na psicose. $\mathrm{Na}$ psicose também há fantasma.

Fantasma, apreço-me a lhes dizer, não é a mesma coisa que fantasia. Vocês já devem saber que o fantasma se refere à relação impossível do sujeito com o objeto. Relação que é impossível pelo fato mesmo de o objeto mental, o objeto psíquico, não ser existente. Portanto, uma relação com um objeto não existente é impossível. Por isso, na Psicanálise, quando se fala de objeto, fala-se de um modo negativo. Sempre se trata do objeto perdido, do objeto recalcado, do objeto representado de um modo não representacional, o "Vorstellungs-repräsentanz", de Freud. Freud não fala de "Objekt-repräsentanz"”, e sim de "Vorstellungsrepräsentanz", ou seja, de uma representação verbal do objeto, da coisa. Ou fala do objeto como "das
Ding", a coisa, que é um modo negativo de falar do objeto, porque a coisa é isso: é a coisa. "Me dá uma coisa, quando falo da coisa". $́$ É algo não definível, é um lugar vazio, que portanto pode ser preenchido por absolutamente qualquer coisa, de um modo certamente não completo. Ou seja, preenchível imaginaria e insatisfatoriamente; não há recobrimento total possível desse lugar da coisa.

O fantasma precisamente designa a instalação do registro da falta desse objeto. Registro que se faz numa instância subjetiva, que tenta se representar para uma posição possível, para aceder à relação com esse objeto, a alguma relação com esse objeto. Ou seja, representa-se numa cadeia significante. Esse sujeito se representa com significantes para dizer a respeito de sua aproximação a esse objeto. $\dot{E}$ por isso que o sujeito fica dividido. Dividido entre o saber e o gozar, entre o saber e o gozo. Quanto mais saber menos gozo, quanto mais gozo, menos saber. Apesar disto, Marquês de Sade tentou reunir saber e gozo na mesma posição, e, para quem não conhece a história, terminou mal. Digamos que ele não foi decapitado por um acaso. Mas terminou seus dias preso na Bastilha, enquanto se produzia a Revolução Francesa. E sua produção mais original desses dias foi exibir sua bunda pela janela e gritar: "Ó cidadãos, vamos ver se desta vez fazem a revolução de verdade". Um episódio não muito edificante. 
Além do mais, porque neste momento a sua bunda era bastante grande, pesava perto de duzentos quilos, mal cabia na janela da Bastilha.

Em todo caso, cabe ao Marquês de Sade o mérito de ter tentado, de ter sido um dos únicos talvez na história que, com persistência e conseqüência, tentou reunir saber e gozo na mesma posição, sustentando a tese de que o ser humano era um ser naturalmente dotado para gozar e que a emergência espontânea de sua natureza, se ninguém se opusesse a ela, conduzi-lo-ia a reunir gozo e saber numa mesma posição. Essa é sua tese em "Filosofia na Alcova", uma tese que, como vocês sabem, Lacan critica num texto que se chama "Kant com Sade", publicado nos "Écrits" em 1966. Lacan, bem como Freud já enunciara, diz: lamentavelmente, não temos nenhum saber natural sobre o gozo. Má sorte a nossa, mas é assim. Nascemos justamente com este déficit de não termos nenhum saber sobre o gozar. Portanto, não temos nenhum saber sobre o objeto, não há um objeto constituído para nós ou pré-constituído para nós, o objeto tem de vir do outro pela via da linguagem. Portanto, quanto mais nos apropriamos deste objeto, quanto mais falamos deste objeto, menor o gozo. Acumulamos um saber sobre esse objeto, mas nos distanciamos dele, e quanto mais nos aproximamos do objeto inexistente, desse lugar vazio, mais podemos gozar de sua ausên- 
cia e menos podemos saber ${ }^{2}$.

Tudo isto para lhes mostrar que esta estrutura mínima está, na verdade, alicerçada num ato de linguagem, ou seja, num ato de marcação pela via da língua e numa posição do sujeito diante deste objeto faltante. E que, então, delimita, marca uma fronteira desse lugar indiferenciado, que é o Real.

Alguém diz esta palavra maravilhosa e misteriosa: “aqui". Esta misteriosa e formidável palavra "aqui". Onde fica "aqui" em relação ao Universo? O que é "aqui"? O "aqui" não é nada. Onde é "aqui"? Qual é o lugar do "aqui"? Mas, vejam só, essa palavra uma vez dita nos tranqüiliza. "Onde estamos?" Estamos aqui. "Ah, se estamos aqui está bem, então não estamos lá”. Dá uma certa impressão de sabermos onde estamos. Agarramo-nos a esta pequena alça, que é a palavra "aqui". Como se isso dissesse alguma coisa da posição imensa, infindável do universo, do tempo, do espaço: é o "aqui". Na verdade, qualquer palavra, em última instância, não diz nada, mas nós, encadeando-a a outras palavras, num sistema de oposições, acabamos por fazê-la designar algo, recolhendo um suposto, uma suposta significância que nos tranqüiliza. E nos oferece, então, a ilusão de sabermos algo do Real. Bom, do Real eu não sei nada, mas sei que estou aqui. Grande saber esse, não é? Não me assegura nada, não me garante nada, mas me deixa tranqüilo, estupidamente tranquiilo durante algumas horas. Se nenhum analista viesse me perturbar neste "aqui", eu até ficaria bastante tranqüilo.

Bem, vejam então o poder que têm os significantes. Na verdade, o ser humano nasce tão sem saber, com tão pouca condição natural de se definir em um saber, que tem de se agarrar a esses significantes. E é em torno desses significantes que ele organiza seu mundo. Para começar lhe colocam um nome. Um nome que não quer dizer absolutamente nada. Justamente porque um significante, para cumprir a função de ser um nome próprio, tem de perder todo o seu conteúdo imaginário. Ferreiro, para ser um nome próprio, um sobrenome, tem de perder a sua função de designar um oficio. Se continua designando o ofício de ferreiro, não é nome próprio: portanto tem de perder sua condição imaginária para operar como nome próprio. Jerusalinsky. O que quer dizer? Sim, tem um significado etimológico, como todos os nomes, na filologia dos nomes se remonta a alguma significação, mas, em última instância, hoje, ele não quer dizer nada. Justamente para me permitir preencher este sobrenome com as significações que, através do meu trabalho e minha vida, eu vou colocando, como todo mundo faz. Então, para começar, colocaramlhe um nome - o ser humano tem essa mania de dar nome a tudo, às estrelas, às pedras, às montanhas, às pessoas, aos bichos. O que, evidentemente, não é um fato natural, porque nada na natureza obriga 
a que as coisas carreguem um nome. É um fenômeno evidentemente simbólico, ou seja, é uma operação de simbolização que o ser humano realiza, que não tem nada que ver com a natureza. E realiza esta operação de simbolização, porque esta lhe é absolutamente necessária para se orientar no mundo. É necessária a ele, ao ser humano. Não é necessária para a natureza, nem para os bichos, nem para as pedras, nem para as coisas. As pedras não sentem nenhuma necessidade de receber um nome. Mas, se nós não colocamos um nome em nosso cachorro, estamos perdidos. Quem vai ter na casa um cachorro sem nome? Alguém tem um cachorro em casa sem nome? É um ato de violência insuportável. Como a gente vai chamar este bichinho? Tem de chamar de alguma maneira. Tudo tem de ter nome. Se a gente se descuida, até nas baratas a gente coloca nome. Em casa, pelo menos, temos uma barata a quem chamamos a " barata invasora". Não conseguimos dar conta dela, por isso estabelecemos uma relação recíproca de respeito. É a "barata invasora". Nós mesmos não sabemos se é sempre a mesma - apesar de que para nós é sempre a mesma - talvez já esteja na segunda, terceira geração...

Quando Lacan reconhece que os significantes têm uma função primordial, fundamental na organização subjetiva e na determinação da constituição de um sujeito, ele está recolhendo estes fenômenos tão simples da vida, como os que acabamos de mencionar. É claro que se nós não estamos dotados de nenhum saber natural acerca das coisas do mundo, o saber que constituímos, constituímolo a partir destes significantes, a partir desta série de significantes, que inventa significações para as coisas. Tudo o que serve para conhecer, para entrar em contato com os objetos, com as coisas do mundo, ou seja, funções psicológicas - a percepção, a motricidade, a inteligência, a fala - tudo isso que serve para operar os intercâmbios com o mundo organiza-se em função deste saber contido no campo significante. Ou seja, a percepção não se organiza de um modo natural, como acontece com os animais, que não falam. Porque a percepção do tigre se organiza em perfeita consonância com a sua "tigridade", poderíamos dizer assim. O tigre vê um coelho, não tem dúvida, nem cogitação: abocanha o coelho e boa noite. Até as considerações psicológicas lhe são alheias, o próximo coelho servirá no momento em que tenha fome. Por outro lado, o ser humano vê o coelho e erra o tiro. Sim, porque "coitadinho, se ele tiver cria, não sei se ele está na época da procriação, e o filho dele, e o coelhinho da Walt Disney? Como é que eu vou matar este coelho?" Ele é chamado à vacilação. Sua percepção não é de tiro no alvo, sua percepção está relativizada, recortada, reordenada, protela- 
da em função da significância. Isto já tinha sido descoberto por Freud, na diferença entre instinto e pulsão.

Sabe-se que Freud descobriu que as leis da percepção não são nem as descobertas por von Helmholtz, em seu Tratado de Óptica, nem tampouco o que Locke e Hume exigiam da Psicologia moderna, contemporânea. Eles exigiam-lhe que demonstrasse uma correspondência entre percepto, percipiens e objeto. Justamente, Freud se dedica a demonstrar o contrário: que não há nenhuma correspondência entre percepto, percipiens e objeto. Não há reunião possível entre essas três instâncias, há uma separação entre o objeto, o percebido e o agente perceptor. O divórcio é para sempre. Há um desencontro irremediável entre estas três instâncias, porque as leis da percepção são absolutamente heterogêneas em relação ao objeto, porque essas dizem respeito à significância, ao passo que os objetos da natureza não significam, são naturais.

Freud, por exemplo, mostra que na alucinação, a percepção está orientada pelas significações, totalmente governada pelas significações, não tendo nada que ver com o objeto da realidade. Essa é uma das primeiras formulações que ele nos propõe em "Introdução ao narcisismo", de 1914. Há uma discrepância absoluta entre o objeto alucinado e o objeto da realidade. Uma discrepância que vem demonstrar esse divórcio. Já na "Traum- 
deutung", ou seja, na "Interpretação dos sonhos", de 1899 ( publicada em 1900), Freud escreve, em "Psicologia dos processos oníricos", que as inibições motoras estão governadas pela significação traumática dos fenômenos evocados. Portanto, já naqueles anos, ele demonstra que a motricidade se organiza não em função de uma lei natural, mas sim em função de um processo mental orientado pelas significações, pela palavra. Bem, o mesmo acontece com o fenômeno da visão, quando ele analisa o fenômeno da cegueira histérica; as alterações perceptivas da visão na histeria ou as pseudoparalisias histéricas, em que demonstra que também as cinestesias estão governadas pela significância. Nos seus "Estudos sobre as afasias", de 1897 , ele também demonstra que os fenômenos de fala estão governados pelos fenômenos de significância, pela instância da palavra. Ou seja, que entre fala e palavra não há identidade. A fala é um derivado da instância da palavra. Ou seja, não é uma função primeira, não é uma habilidade autônoma.

Poderíamos dizer muito rapidamente que os psicólogos do ego, como Hartmann, Lowenstein, e também Anna Freud estão redondamente equivocados quando supõem que as funções psicológicas como a inteligência, a percepção, a fala e a motricidade são autônomas, e que se a conflitiva psíquica não as invade elas se desenvolvem de um modo perfeito, autônomo e funcionam muito bem. Não é de 
jeito nenhum assim. Tão absolutamente dependentes dos significantes elas são para se organizar - tão absolutamente dependentes do campo da palavra elas são para funcionar - que quando a palavra não as toca com a suficiente eficácia, o sujeito psíquico se decompõe nos fenômenos elementares. Fenomênos que consistem na manifestação independente mas caótica dessas funções psicológicas. Assim o raciocínio lógico pode funcionar, pode funcionar a percepção escópica, pode funcionar a motricidade, de um modo verdadeiramente autônomo, precisamente naquele quadro que se caracteriza centralmente pelo fato de os significantes não organizarem estas funções, ou seja, a psicose.

Uma percepção não recortada e ordenada pela eficácia do significante, ou seja, alucinatória. Uma enunciação não governada pela relação com o Outro, então delirante. Uma fala não orientada pelo campo da palavra, portanto ecolálica. Uma motricidade não governada pela separação e alterização, portanto, uma gestualidade ecomímica: numa supressão da distância do outro, uma pura mimese, ou uma pura movimentação imitativa, ou uma agitação psicomotora sem direção. A eventual manifestação de fenômenos de ressonância, em qualquer uma dessas funções psicológicas. Por ressonância se entende a produção, por parte do sujeito, de um evento de suficiente intensidade, em qualquer uma dessas funções, para provocar um efeito em eco dessa mesma produção, ou seja, constituir ali, na auto-referência, já que não pode constituir uma referência alterizada, para organizar sua percepção, sua fala, sua movimentação, seu raciocínio. Último recurso já que não pode organizá-los em função de nenhuma significância ${ }^{3}$.

Eis aí, então, que o psicótico se vê na necessidade de produzir o arremedo de alguma significância, através da produção de um delírio, de uma mimese, de uma invenção, de uma ressonância, de uma repetição, de uma estereotipia, ou seja, procura reencontrar algum traço que lhe permita saber que é ele mesmo que saiu de trás da porta e se encontra agora no meio do quarto. Porque nada na sua organização natural o informa de sua "mesmidade", como informa ao tigre sobre sua própria delimitação imaginária. Porque o tigre se reencontra no imaginário do coelho, cada vez que o coelho aparece, ou da "tigra", cada vez que a "tigra" aparece. E aqui o ponto mais crítico do ser humano: se o tigre se reconhece na "tigra" pela implicação instintiva em que a "tigra" o coloca, o homem não se reconhece na mulher, porque nada instintivo o implica aí. Pelo menos não imaginariamente. A menos que alguma significância o tenha inscrito do lado da masculinidade, assinalando-lhe a falta de mulher. Instintivamente, nada o informa de sua 
"mesmidade", este é o lugar mais vazio no ser humano. O ser humano pode tomar como objeto de sua sexualidade absolutamente qualquer coisa, até um tubo fluorescente, até um elefante e uma formiga, até um planeta. Como dizia aquele psiquiatra a quem o pai foi consultar, porque seu filho tinha, segundo o psicólogo, uma obsessão sexual. $O$ psiquiatra diz ao pai que desenhe alguma coisa para o filho. $O$ pai desenha um círculo. Então, o psiquiatra the diz: "Ora, com as coisas que o senhor lhe desenha, como quer que ele não seja um obsessivo sexual?" É evidente que, no círculo que o pai desenhou, o psiquiatra viu um desenho sexual. Aliás, podemos ver desenhos sexuais em qualquer coisa. As crianças fazem esses desenhinhos de uma gorda agachada buscando um sabonete (representada por um círculo com, um raio traçado). É uma atribuição de significância a um desenho que pode ser qualquer outra coisa.

Isso é para lhes demonstrar de um modo mais ou menos rápido que aquilo que nos parece tão naturalmente organizado - as percepções óptica, auditiva, tátil, a interpretação das coisas no mundo, o raciocínio, a fala, nossa motricidade - não tem nenhuma organização natural. A tal ponto que, quando falta o significante que organiza essas funções, seu ordenamento é profundamente perturbado, e as coisas acontecem de um modo completamente diferente daquele que estamos acostumados a reconhecer como normal. Ou seja, a percepção já não é a mesma, a fala não é a mesma, a movimentação não é a mesma. Todo mundo aqui deve ter alguma experiência com a movimentação dos psicóticos, a agitação, as contraturas... Vocês sabem que há quadros críticos esquizofrênicos que chegam ao ponto de produzir fraturas dos ossos, tamanha a intensidade da contratura muscular a que esse corpo fica submetido; chegam a produzir fraturas graves, fraturas expostas.

Vamos, então, fazer uma breve revisão de quais são as formas de manifestação disto que se chama "fenômenos elementares": redução das manifestações psíquicas aos elementos primários, no sentido que S. Freud dava àquilo que denominava "sintoma primário"; a manifestação corporal quando o aparelho psíquico entra em pane, ou seja, quando a função não é orientada pela palavra.

Eu fiz a análise de alguns desses fenômenos elementares: no campo da linguagem, no campo da percepção, no campo do corpo e no campo motor. Primeiro vamos ver a psicose esquizofrênica e a psicose paranóica.

Estamos falando das manifestações precoces. Precoces em dois sentidos: ou bem cedo na vida, ou bem cedo no desenvolvimento da crise, no aparecimento da crise. É sabido que a manifestação da crise psicótica aparece inicialmente com uma série de fenômenos, que Clérambault chamou de fenômenos crepusculares, que aludem a uma 
espécie de crepúsculo da personalidade, uma espécie de apagamento das condições subjetivas. Esse apagamento é correlativo à emergência cada vez maior da manifestação disto que chamamos fenômenos elementares, que são fenômenos de estranhamento. Ou seja, a percepção se desorganiza ao ponto de não poder reconhecer os traços da própria imagem.

Analisemos um dos fenômenos elementares que estávamos vendo aqui: os fenômenos de fala "dessubjetivada", por exemplo o aparecimento da ecolalia, o aparecimento de uma linguagem fragmentada, que é ineficaz. O sujeito se queixa, na esquizofrenia, num momento prévio à crise, de que suas palavras não têm efeito, são palavras vazias. Ele faz o esforço de falar, mas é como se as palavras fossem formas vazias. A sensação que ele tem é de que fala, fala, fạla, e isso não diz nada, não causa nenhum efeito nos outros, nem em si próprio. Às vezes a queixa é de que a fala mental vai adiante do que ele diz, e ele nunca consegue alcançála. O que diz já está esvaziado de significação, é uma espécie de esvaziamento da linguagem. Já na psicose paranóica, o que aparece é uma forma delirante, ou, com uma certa freqüencia, uma alucinação auditiva, sob a forma de uma linguagem plena, ou seja, alguém fala para o sujeito e diz tudo que precisa ser dito, fecha o sentido com um mandato. Por exemplo, um paciente, cujo primeiro fenômeno elementar apareceu no cinema, 
num cinema pornô, em que ele escutou a voz de seu pai lhe dizendo: "saia imediatamente daí de olhos fechados". E ele disse: "isso é tudo que eu precisava ouvir". Não precisava ouvir mais nada que isso para saber o que tinha que fazer na vida. O que colocava o outro em uma posição de controle real, de seus pensamentos e de sua vida erótica.

A percepção na psicose esquizofrênica aparece de forma alucinatória, predominantemente visual, referida a um objeto delirante ${ }^{4}$. No entanto a percepção do objeto delirante nas psicoses paranóicas se refere à certeza com que o paranóico concebe a presença de certos objetos persecutórios que ele não vê, nem percebe materialmente, mas que instala discursivamente como existentes.

Vamos tomar, como exemplo, uma paciente paranóica que está há 12 anos em tratamento e que continua tão paranóica como sempre, para que não se tome $o$ que vou lhes dizer como uma promessa de cura. Em todo caso, sim, vamos falar dos limites da cura na psicose, da dimensão da cura na psicose. Por sinal, as intervenções podem ter efeitos de cura limitada. Esta paciente tem conseguido estruturar uma 'metáfora delirante não paterna', que lhe serve de referente simbólico, e que tem permitido a ela organizar fragmentos importantes da sua vida. Já faz alguns anos que ela trabalha, circula socialmente, não está internada, ganha seu dinheiro, tem seus ami- 
gos, vai ao cinema, enfim, tem uma vida que poderíamos chamar de globalmente normal e, claro, não olha normalmente para ninguém. Ela entra em qualquer lugar e deixa todo mundo com o pé atrás, porque em seguida entra nessa implicação do olhar, onde há uma certa ferocidade suposta no outro, que a coloca em posição agressiva, o que torna suas relações sociais sempre bastante complicadas. Mas apesar disso, ela consegue uma certa circulação. Porém, no momento em que entra em delírio - o que acontece com uma certa freqüência, a cada dois, três, cinco meses, dependendo das circunstâncias da vida - ela pede para que, por favor, eu chame os pedreiros para tirar todos os microfones que estão enxertados na parede de meu consultório. É ali que me vejo com problemas, porque, evidentemente, não posso estar demolindo meu consultório. Aliás, nunca demoli o meu consultório, mas ela confia em que eu já tenha mandado o pedreiro fazer uma exploração com sondas para ver se realmente lá estavam os microfones. E além dos microfones, há os aviões e helicópteros que estão destinados a vigiar. Com toda a certeza alucinatória, ela chega a escutar o zum-zum dos helicópteros e aviões - e quando passam aviões e helicópteros de verdade, ela tem um material facilitado, não precisa alucinar nada. Mas quando não passam, ela igualmente os escuta e esperamos que terminem de passar para ela poder continuar falando. Ou seja, instala um objeto delirante, e apesar de não vê-lo - evidentemente ela não vê o microfone na parede, não precisa vê-lo - ela tem toda a certeza de que eles estão ali. Mais ainda, se ela não escuta os aviões é porque eles estão voando com silenciador!

A respeito do corpo, vocês sabem que há uma diferença entre esquema e imagem corporal. É uma diferenciação que inicialmente foi assinalada por um analista austríaco, que se chama Paul Schilder e que, posteriormente, mereceu outros estudos, dentre eles, notadamente, o de Françoise Dolto, num livro que se chama "A imagem inconsciente do corpo", editado em português em 1992. Eu mesmo escrevi algumas questões sobre este assunto (Jerusalinsky, 1990). A concepção que prefiro destacar parece lançar mais luz sobre esta questão: cabe diferenciar o esquema, que é efeito do que no campo do Imaginário produz o real do corpo, enquanto a imagem propriamente dita está determinada pelos efeitos que o registro Simbólico provoca no Imaginário. Vocês sabem que Lacan tem 3 conceitos de real: o primeiro é o que tem que ver com o orgânico, ou seja, a impossibilidade corporal, o impossível enquanto limite corporal. $O$ segundo se refere à impossibilidade lógica. E o terceiro à impossibilidade ética. A respeito do primeiro, nós podemos falar com nossas células, nossos ácidos nucleicos, mas eles não se modificam em função 
do que estamos lhes dizendo. Existe um limite corporal, nós estamos constituídos de um modo biogenético que não responde ao campo da palavra. E nós respondemos pelo campo da palavra e pelo campo da palavra enquanto seres, e não enquanto nossa constituição orgânica. Por mais que falemos com nossos cromossomos, nossos cromossomos continuam ali como sempre. É necessário pontuar isso porque há um psicólogo religioso, Frei Albino Aresi, que tem dito, por exemplo, que a Síndrome de Down se cura falando intensamente com o cromossomo do doente e que a trissomia depende do desejo da mãe! Eis ali um bom exemplo disso que chamamos de 'objeto delirante'. Justamente, o que Lacan diz é que é fundamental o significante não funcionar como real, porque, nesse caso ele opera numa posição de rebaixamento, de desconhecimento, de apagamento de seus referentes. Entre os fenômenos de psicotização há um caso particular que poderíamos chamar de 'psicose artificial' provocado na Guerra Civil, em Moçambique, na África, através de obrigar os filhos de reféns capturados a matar seus pais. Como o sujeito entra dentro de um impossível ético, entra num estado de 'psicose artificial'. E é tão difícil o retorno quanto o retorno de uma psicose originária, não é nada fácil sair ... há alguns que não saem nunca mais.

Referimo-nos a esses três conceitos de Real, porque é a partir do Real, este primeiro conceito, que é o real orgânico, que a 'imagem corporal' fica presa a isso que se chama 'esquema corporal', que é o saber pré-consciente que temos sobre os limites de movimentação de nosso próprio corpo. Nós sabemos que se obrigarmos nosso corpo a uma torção maior do que ele suporta, vai se quebrar. Podemos pular de certa altura, podemos girar em uma determinada velocidade, podemos pegar nossa orelha de certo modo, mas uma inversão completa entre a metade superior e a inferior de nosso corpo é impossível.

Isto é o que se chama de esquema corporal. O esquema corporal reconhece limites provocados pelo registro do Real orgânico, registro que somente é possível quando o campo da palavra o diferencia, distiguindo, então, Real, Simbólico e Imaginário. Por outro lado, a imagem corporal, oriunda do simbólico, origina-se no conjunto das significacões que se atribuem ao corpo. Por essa via a imagem corporal entra no âmbito da fantasia. Enquanto imagem, simbólica, nosso corpo pode ser um corpo voador, ter um tamanho incomensurável, não tem limitações de transformação, a não ser as impostas pela lei que regula o Simbólico.

Por isso, o que acontece com o corpo na psicose, na medida em que se perturbam a lei e a percepção, afeta tanto a ordem do esquema como a ordem da imagem. A perturbação do esquema afeta, fun- 
damentalmente, o motor, ou seja, desorganiza, transforma o princípio organizacional desse motor. Enquanto a transformação que se produz no nível da imagem corporal, oriunda das claudicações simbólicas sofridas na psicose, envia o corpo ao mesmo estatuto do 'objeto delirante'.

Por isso na esquizofrenia, como o que claudica na simbolização é, fundamentalmente, a posição simbólica do olhar do outro, enquanto unarizante - ou seja, o olhar do outro como referente simbólico da condição subjetiva perde-se a referência do outro como unarizante, como assinalador da singularidade. Por isso a imagem corporal se fragmenta. Uma forma clássica de esquizofrenia consiste na queixa de que falta um órgão do corpo ${ }^{5}$.

Vejamos um monólogo esquizofrênico:

- Olha, Dr., estou vindo vê-lo porque estou morto. Estou morto porque não tenho coração. Estou vendo se eu consigo um coração. Será que o senhor poderá me enxertar um coração? Talvez desse modo possa estar vivo.

Vejamos um diálogo esquizofrênico:

- Doutor, me falta o fígado.

- Mas não pode lhe faltar o fígado, sem fígado a pessoa está morta.

- Pois é, é isso o que está me acontecendo, eu estou morto!

- Mas como está falando?

- Ah, não, é que a gente fala morto. 
Temos ali um delírio esquizofrênico. Vejamos outro:

- Eu fui comido por uma baleia.

- Mas como se o senhor está aqui?

- Estou falando de dentro da barriga da baleia.

Ou seja, a posição do corpo faz margem à construção desse delírio, que irá suprir o lugar do Outro, que já não mais cumpre essa função de assinalar a posição do sujeito. É por isso que aparece um lugar vazio, um fragmento, um pedaço: "por favor, me alcança minha cabeça que está sobre sua escrivaninha". Não adianta lhe dizer que a cabeça está colada em seu corpo, porque ele tem a nítida percepção de que sua cabeça está ali, e além do mais a vê. Não é que ele a imagina, ele a vê.

Uma conhecida anedota sobre o delírio esquizofrênico ${ }^{6}$ : um louco, considerado muito bonzinho, gostava de tocar o violão. Embora não tivesse nenhum violão, ele cantava e tocava um violão. Todo mundo lhe dava de comer, era o louco simpático do povo. Tanto que um dia, o prefeito decidiu fazer uma obra de bem e lhe comprou um violão. Então, num ato público - claro, ele não ia perder a oportunidade de conquistar alguns votos -, fez a entrega solene do violão para o louco. O louco: "muito obrigado", deu-lhe um abraço, muito grato. Ato seguido, ele coloca o violão ao lado e começa a cantar e tocar no seu 
violão imaginário. Então, surpreso, o prefeito lhe diz:"O que acontece? Não gostou do violão?" E ele responde: "Sim, agora tenho dois".

Ou seja, a organização da percepção não depende de nada natural, nem de nada físico, depende da posição que o significante ocupa. Por isso se na psicose esquizofrênica a imagem do corpo é fragmentária, na psicose paranóica o mais característico do modo como se organiza a imagem corporal é ela ser bissexual. Na paranóia, o que não se opera é a castração, porque o sujeito fica identificado com um Grande Outro absoluto, ou seja, um Grande Outro que não está dividido, a quem não falta nada. Como é absoluto, não reconhece a castração, ele é homem e mulher ao mesmo tempo, Deus e homem ao mesmo tempo. Há aí um delírio de Ser.

No nível motor, na psicose esquizofrênica, temos a ecomimia, a imitação mimética. Na qual o sujeito produz uma gestualidade imitativa, em espelho, daquele que vê na frente.

$\mathrm{Na}$ crianças, na esquizofrenia, aparece algo que podemos chamar de 'delírio motor', que consiste na passagem de um objeto a outro, sem se deter em nenhum, nem sequer dando tempo para percebê-lo. Esta é uma forma de comportamento muito comum nas crianças psicóticas precoces, que passam de uma coisa a outra, sem poder parar em nada, num estado de agitação constante. Pegam um objeto, e logo pegam outro e o soltam, sem chegar a fazer nada com nenhum deles. Como a criança não tem um domínio no campo da linguagem, ela está pouco iniciada nos recursos lingüísticos. Essa passagem sem solução de continuidade de uma coisa a outra ocupa o lugar no adulto do delírio taquilálico, uma forma de fala completamente acelerada, sem intervalo. O sujeito não pára nem para respirar, é capaz de se asfixiar falando. Não pode parar de falar, porque ao parar, angustia-se de um modo insuportável. Não pode escutar nenhum espaço vazio. Quando escuta o silêncio entra numa angústia siderativa, porque o que sustenta um mínimo de organização, um mínimo de subjetivação é esta fala constante. Já que ela consiste na perseguição de algum traço que possa unarizar, ou seja, que possa constituir alguma posição singular para interpretar, compreender, decifrar a posição - em última instância dispostos arbritariamente pelo discurso - desses objetos com os quais tropeça. Não é um delírio sistemático, ou seja, não é um delírio organizado do ponto de vista racional, justamente porque, como fracassa a organização racional do delírio, não chega a constituir uma significância. Como não pode construir uma significância, tem de preencher esse vazio continuando a falar. Justamente quando consegue produzir alguma formação metafórica, o sujeito se acalma. Uma forma possivel de intervenção analítica é ajudar este sujeito 
delirante taquilálico ou hipercinético a produzir alguma metáfora e fazê-lo notar que produziu um sentido. Porque na aceleração de sua própria fala, pode passar por cima do fato de ter produzido um sentido, sem se dar conta, e continuar adiante, tomado pela ansiedade de não ser assaltado pelo silêncio.

$\mathrm{Na}$ psicose paranóica, há uma alternância entre a ação agressiva e a passividade. No momento em que o sujeito paranóico fica identificado com Grande Outro, ele fica sendo Deus e entra num estado contemplativo. Mas, no momento em que ele se descola desta posição do Outro, então, o Outro se transforma em alguém absoluto que exige dele uma resposta impossível. O nível de perseguição que ele experimenta é tão feroz, que tem de se defender agressivamente. O momento de agressividade do paranóico é projetivo, e sua agressividade não é, nesse momento, virtual, mas real.

É fundamental para quem pretende trabalhar com psicóticos familiarizar-se com estas manifestações clínicas, e sua leitura. Já que, sendo esses alguns dos fenômenos clínicos mais frequentes nas psicoses, eles marcam a posição em que somos implicados na transferência. O que equivale a dizer qual é o semblante que precisamos suportar, e em que significância - no duplo sentido de quanto de incidente, de significativa, e qual a significação - será tomada nossa intervenção.

\section{REFERÈNCIAS BIBLIOGRÁFICAS}

DOLTO, F. A imagem inconsciente do corpo. São Paulo, Perspectiva, 1992.

- FREUD, S. (1914). "Sobre o narcisismo". In: Obras completas de Sigmund Freud. Rio de Janeiro, Imago, 1976, v.7.

- FREUD, S. (1900). “A interpretação dos sonhos". In: Obras completas de Sigmund Freud. Rio de Janeiro, Imago, 1976, v. 4 e 5.

- JERUSALINSKY, A. A formação da imagem corporal. In: Escritos da Criança. Porto Alegre, Centro Dra. Lydia Coriat, 1990, ano 3, n.3.

- LACAN, J.(1963). "Kant avec Sade". In: Écrits. Paris, Seuil, 1966

NOTAS

'Seminário proferido no Instituto de Psicologia da USP, no dia 11/03/96. A transcrição e a edição, realizadas por Ilana Katz e Flávia Vasconcellos, foram revistas pelo autor. 
2 Cabe lembrar que, em "Mais Além do Pricípio do Prazer", S. Freud sublinha que no jogo do Fort-Da a criança goza da repetição da ausência.

${ }^{3}$ Ver LECOURT, E. "Du cri”. In: Freud et le sonore. Paris, L'Harmattan, 1992, pp. 21-31. Ver também CZERMAK, M. "Folie Résonnante". In: Passions de L'objet. Paris, Joseph Clims, 1986, p. 163.

${ }^{4}$ Chamamos 'objeto delirante' um objeto mentalmente construido, tal que, existente ou não na realidade, venha a cumprir uma função de referente real no comportamento e no raciocínio do sujeito com total independência de sua posição simbólica, ou seja, de sua significação no Campo do Outro. Ele tem muito mais a função de realizar o ilusório - para resguardar essas consistência apenas precária que o sujeito consegue estruturar - do que vir a calhar no lugar de uma falta.

${ }^{5}$ Ver sobre a Síndrome de Cotard em CZERMAK, M. Passions de L'objet, op. cit, pp. 205-237.

"Citada pelo escritor Eduardo Galeano em "O livro dos abraços". 